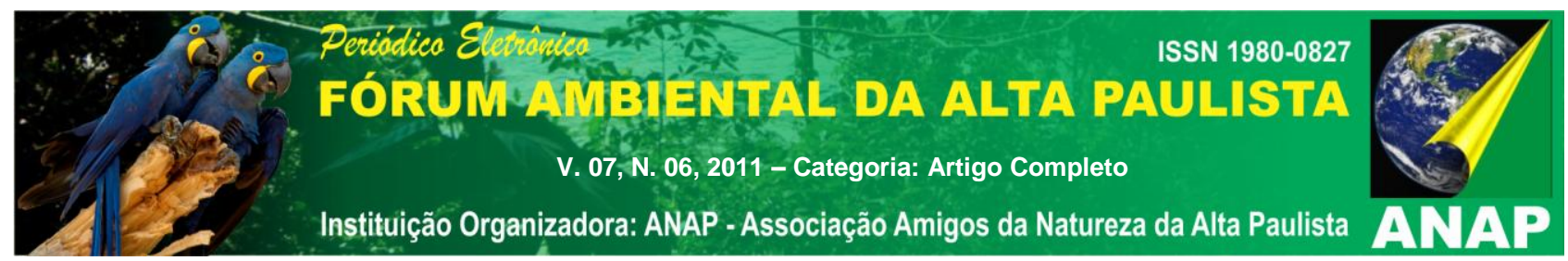

\title{
EDUCAÇÃO AMBIENTAL E RESÍDUOS SÓLIDOS EM PRESIDENTE PRUDENTE: O PAPEL DA COOPELIX
}

\author{
Alba Regina Azevedo Arana ${ }^{1}$ \\ Augusta Boa Sorte Oliveira Klebis ${ }^{2}$
}

RESUMO: O projeto "Educação Ambiental e Resíduos sólidos em Presidente Prudente-SP: o papel da Cooperlix" nasceu da convergência de pesquisadores e instituições que buscavam formas de intervir na grave situação de degradação ambiental e exclusão social relacionada ao lixo em Presidente Prudente. O principal elemento aglutinador foi a potencialidade de se estabelecer interlocução em uma equipe interdisciplinar e interinstitucional, objetivando cumprir o papel de fomentar políticas públicas para o gerenciamento integrado de resíduos sólidos. Apresenta-se também, a experiência de projeto de políticas públicas, realizado em parceria por várias instituições públicas e particulares, com expressiva participação das universidades (UNOESTE, UNESP); a situação dos resíduos sólidos em Presidente Prudente; e informações básicas sobre a Cooperativa de Trabalhadores de Produtos recicláveis de Presidente Prudente (COOPERLIX), suas potencialidades, dificuldades e necessidades.

Palavras-chave: educação ambiental; resíduos sólidos; Coopelix

\section{INTRODUÇÃO}

Para fundamentar a proposta, apresenta-se a situação dos resíduos sólidos em Presidente Prudente; realizado em parceria por várias instituições públicas e particulares; e informações básicas sobre a COOPERLIX, suas potencialidades,

\footnotetext{
${ }^{1}$ alba@unoeste.br. Diretor Faclepp. Professora de Geografia Pós-Graduação em Gestão Ambiental- UNOESTE, Rua Melen Isaac, 21, Jardim das Rosas, Presidente Prudente-SP. 2 augusta@unoeste.br. Coordenadora curso Pedagogia - UNOESTE - Av. Cel Marcondes, 3.397, Jardim Bongiovani, P. Prudente-SP.
} 


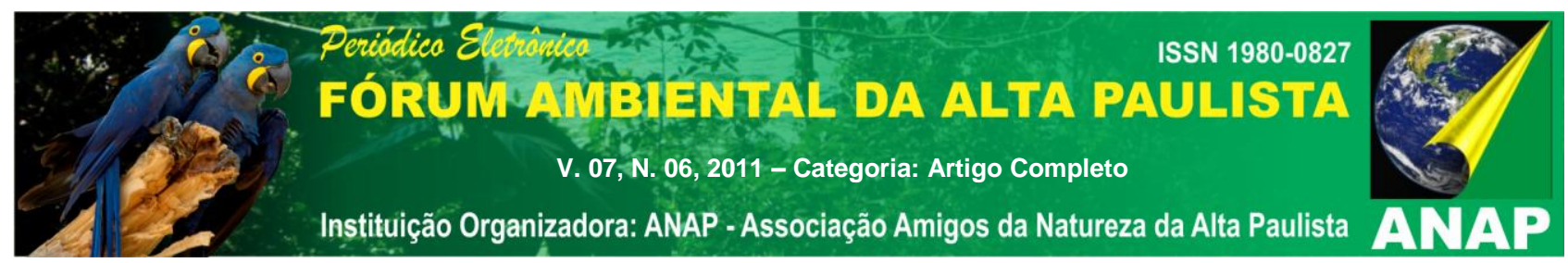

dificuldades e necessidades. Apresenta-se, também, plano de trabalho para efetivar campanhas educativas na cidade e ampliar a coleta seletiva.

O projeto "Educação Ambiental em Presidente Prudente-SP: o papel da Cooperlix" nasceu da convergência de pesquisadores e instituições que buscavam formas de intervir na grave situação de degradação ambiental e exclusão social relacionada ao lixo em Presidente Prudente. O principal elemento aglutinador foi a potencialidade de se estabelecer interlocução em uma equipe interdisciplinar e interinstitucional, objetivando cumprir o papel de fomentar políticas públicas para o gerenciamento integrado de resíduos sólidos.

No projeto adota-se a Educação Ambiental como elo fundamental para a implementação do gerenciamento integrado dos resíduos sólidos no município, compreendendo-a como um processo educativo, permanente e contínuo, que visa desenvolver uma filosofia de vida ética e moral, de maior harmonia e respeito com a natureza e entre os homens, propiciar conhecimentos e o exercício da cidadania para uma atuação crítica e consciente dos indivíduos e grupos.

Para fundamentar a proposta, apresenta-se a experiência de projeto de políticas públicas, realizado em parceria por várias instituições públicas e particulares, com expressiva participação das universidades; a situação dos resíduos sólidos em Presidente Prudente; e informações básicas sobre a Cooperativa de Trabalhadores de Produtos recicláveis de Presidente Prudente (COOPERLIX), suas potencialidades, dificuldades e necessidades. Apresenta-se, também, plano de trabalho para campanhas educativas na cidade, com a participação de universitários, visando ampliar e melhorar a coleta seletiva, criar novas vagas e aumentar a renda dos cooperados

\section{O PROJETO DE POLÍTICAS PÚBLICAS}

O projeto "Educação Ambiental e gerenciamento integrado dos resíduos sólidos em Presidente Prudente-SP: desenvolvimento de metodologias para coleta 


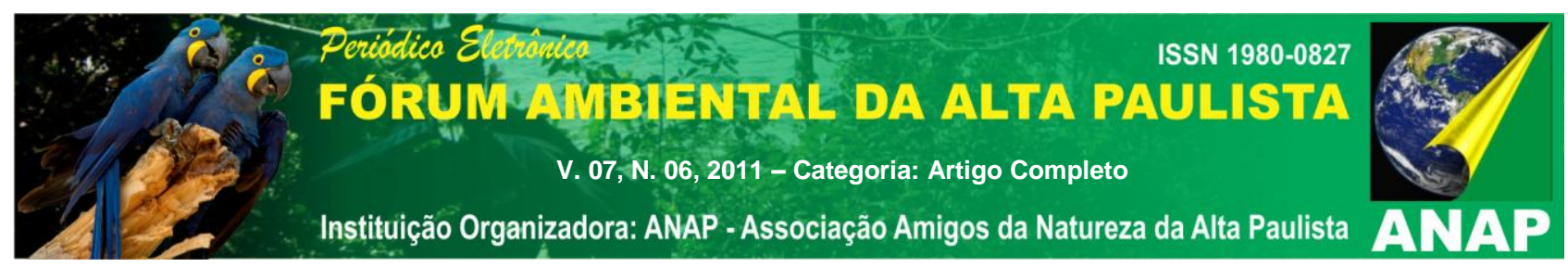

seletiva, beneficiamento do lixo e organização do trabalho" nasceu da convergência de pesquisadores e instituições que buscavam formas de intervir na grave situação de degradação ambiental e exclusão social relacionada ao lixo em Presidente Prudente. O principal elemento aglutinador foi a potencialidade de se estabelecer interlocução em uma equipe interdisciplinar e interinstitucional, objetivando cumprir o papel de fomentar políticas públicas para o gerenciamento integrado de resíduos sólidos.

O desenvolvimento do projeto, considerando as Fases I e II (2001 a 2005), diretamente apoiadas pela FAPESP, e a Fase $\mathrm{II}^{3}$, desde janeiro/2006, visa produzir diversos impactos para as instituições da administração pública municipal (secretarias, autarquias, etc.), com destaque para a formulação, avaliação e gestão de políticas públicas relativas aos resíduos sólidos em Presidente Prudente. No projeto adota-se a Educação Ambiental como elo fundamental para a implementação do gerenciamento integrado dos resíduos sólidos no município, compreendendo-a como um processo educativo, permanente e contínuo, que visa desenvolver uma filosofia de vida ética e moral, de maior harmonia e respeito com a natureza e entre os homens, propiciar conhecimentos e o exercício da cidadania para uma atuação crítica e consciente dos indivíduos e grupos, atendendo aos objetivos, princípios e finalidades da Educação Ambiental expressos na Conferência de Tbilisi (Dias, 1994) ${ }^{4}$.

Ao longos das Fases I, II e III progressivamente foram se formando parcerias, envolvendo um amplo leque de agentes sociais e instituições públicas e particulares, entre as quais destacam-se: Faculdade de Ciências e Tecnologia/UNESP, Universidade do Oeste Paulista (UNOESTE), Prefeitura Municipal de Presidente Prudente, Companhia Prudentina de Desenvolvimento (PRUDENCO), Fundo Social de Solidariedade, Federação Nacional dos

\footnotetext{
${ }^{3}$ Fases estabelecidas no Programa de Políticas Públicas da FAPESP. Para Fase III não há apoio direto desta Fundação e é fundamental a continuidade das ações pelas instituições diretamente envolvidas no projeto, fortalecendo e ampliando as parcerias.

${ }^{4}$ DIAS, G. F. Educação Ambiental Princípios e Práticas. 4.ed., São Paulo: GAIA, 1994.
} 


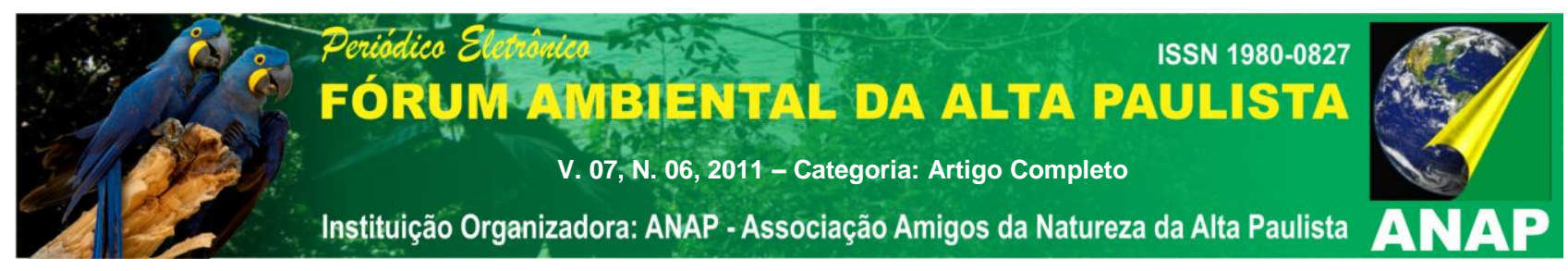

Trabalhadores em Serviços, Asseio e Conservação, Limpeza Urbana, Ambiental e Áreas Verdes (FENASCON) e Sindicato dos Empregados em Empresas de Asseio e Conservação e Trabalhadores na Limpeza Urbana de Presidente Prudente e Região (SIEMACO), com apoio da Fundação de Amparo à Pesquisa do Estado de São Paulo (FAPESP), Núcleo 3R da Universidade Federal de São Carlos, Fundação Banco do Brasil, escolas públicas e particulares, empresas dos setores industrial, comercial, agroindustrial e instituições financeiras e religiosas, entre outras.

\section{A SITUAÇÃO DOS RESÍDUOS SÓLIDOS EM PRESIDENTE PRUDENTE - SP}

O município de Presidente Prudente, com aproximadamente 200 mil habitantes e taxa de urbanização de $98 \%$, trata-se da única cidade de porte médio num raio de cerca de 150 km no extremo oeste do Estado de São Paulo.

Constitui-se em um centro regional que abrange em sua área de influência vários municípios paulistas e de outros estados brasileiros (Mato Grosso do Sul e Paraná). As atividades comerciais e de serviços (especialmente as relacionadas à saúde e educação) são as principais responsáveis pela definição desta centralidade interurbana, já que se localizam de forma concentrada nesta cidade e geram fluxos permanentes de pessoas e mercadorias. Essa concentração populacional e de comércio/serviços é responsável pela geração de aproximadamente $200 \mathrm{t}$ /dia de resíduos sólidos urbanos, a maioria dos quais ainda sem destinação adequada (em lixão), a despeito de todos os esforços que vem sendo envidados pelo poder público municipal e parceiros para seu tratamento adequado.

A coleta de resíduos sólidos abrange $100 \%$ da malha urbana, nos cerca de 55.500 domicílios. É realizada pela PRUDENCO, que também cuida da limpeza urbana, incluindo a varrição de ruas, capina, poda de árvores, limpeza de bueiros e disposição do lixo. A freqüência da coleta é variável entre os bairros (há bairros 


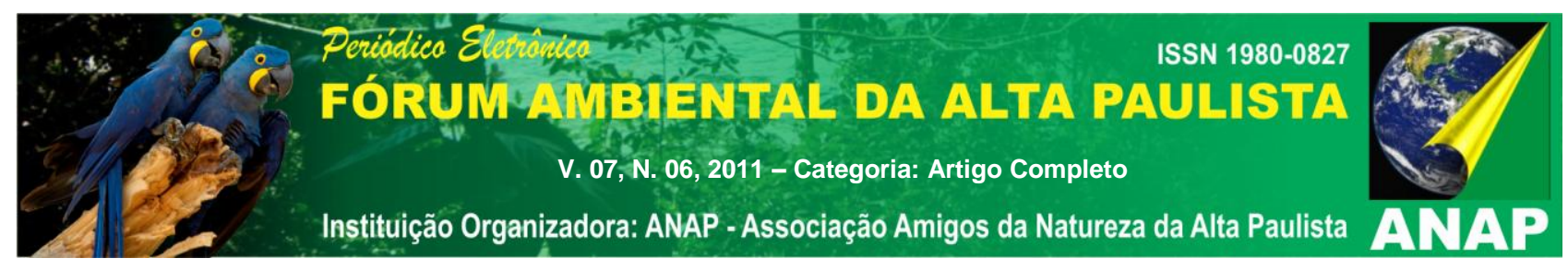

com coleta diária e outros em 3 dias na semana, alternadamente) e entre esses e a área central (com coleta diária). No que se refere à coleta de lixo, limpeza urbana, varrição de ruas e capinas, Presidente Prudente destaca-se como uma das cidades mais limpas e organizada do país.

Todavia, ainda enfrenta problemas com a disposição do lixo coletado, atualmente realizada no lixão localizado no Distrito Industrial I "Antonio Crepaldi", provocando impactos ambientais significativos nos solos, córregos, água subterrânea e no ar, em razão do escoamento e infiltração de chorume e queima do lixo pelos catadores que ali trabalhavam. A proximidade com o Distrito Industrial e bairros populares geram outros problemas, como mau cheiro, proliferação de vetores de doenças e desvalorização de imóveis urbanos e rurais.

O lixão representa hoje um dos maiores problemas ambientais do município de Presidente Prudente. Fechá-lo e construir um aterro sanitário constitui uma forte demanda dos agentes públicos da área ambiental do estado e da promotoria pública, com desdobramentos políticos e sociais (como a retirada dos catadores). Apesar de estar em trâmite o processo de licenciamento ambiental de área para implantação do aterro sanitário do município, com elaboração de EIA-RIMA (Estudo de Impacto Ambiental e Relatório de Impacto no Meio Ambiente), instrumentos exigidos na legislação ambiental brasileira, a aprovação e construção do aterro ainda não têm previsão. A previsão de implantação do aterro sanitário é para até final de 2012, reforçando a importância de descarte seletivo e coleta seletiva no município.

A construção do aterro sanitário virá resolver um problema histórico de Presidente Prudente, uma vez que sempre se dispôs o lixo de forma irregular em cabeceiras de drenagem e fundos de vales, em lixões localizados nas periferias da malha urbana, pondo em risco a qualidade ambiental e de vida da população.

Na história do município adotou-se a prática de dispor os resíduos sólidos para além da malha urbana, não se considerando a direção dos ventos, localização de mananciais e proximidade com residências, especialmente por 


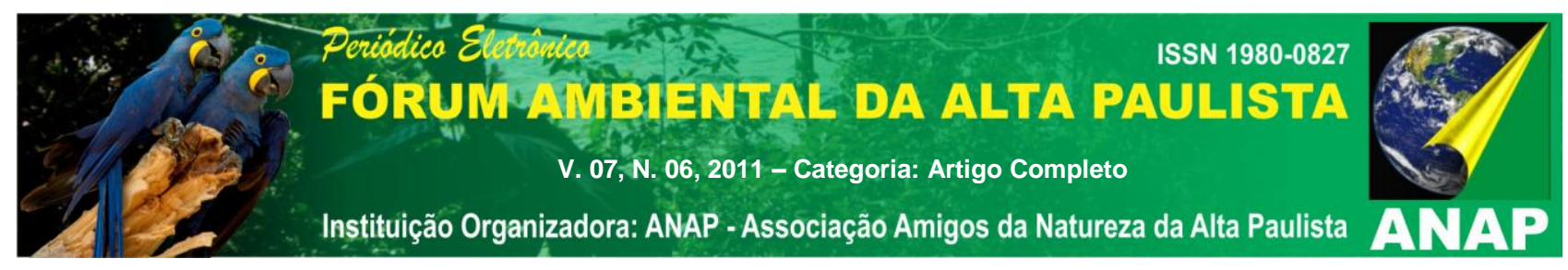

serem, em sua maioria, bairros pobres (LEAL et al, 2004). Entretanto, com a expansão urbana, muitas áreas de disposição e seu entorno imediato foram incorporados aos novos bairros como locais que abrigam praças, campos de futebol, creches e escolas, alguns dos quais apresentam problemas de subsidência, afetando estrutura de construções, e contaminação das águas subterrâneas.

O município também tem graves problemas com os RSSS, os quais são recolhidos e tratados em autoclave da UNOESTE, antes de serem dispostos em área contígua ao lixão. Embora a legislação obrigue o gerador a dar o tratamento e destino adequado a este tipo de RSU, a responsabilidade ainda recai sobre o poder público municipal, notadamente por serem resíduos patogênicos e o serviço de coleta diferenciado ser realizado pela PRUDENCO.

Entulho e restos de podas são destinados para bolsões, onde são reaproveitados para garantir a trafegabilidade de estradas rurais, no caso de entulho, ou para fornecimento de lenha para caldeiras e fornalhas, no caso das galhadas, que tem sua comercialização realizada pelos cooperados.

Sobre os resíduos de origem industrial quase não há dados e informações disponibilizados e os geradores, normalmente, se recusam a fornecê-los. Estudos realizados como pesquisas de iniciação científica e de acompanhamento de órgãos públicos da área de meio ambiente, indicam que ainda não há no município e região um aterro industrial.

Um dos fatos mais graves no que se refere aos resíduos sólidos urbanos no município, era a presença de catadores no lixão. Até recentemente, cerca de 100 catadores de materiais recicláveis, em condições precárias e com graves riscos à saúde. De acordo com os dados e informações levantados no projeto de políticas públicas, através de aplicação de questionários e cadastro diretamente no lixão, verificou-se que, dos catadores entrevistados, $66 \%$ são homens e $34 \%$ mulheres. As faixas etárias situam-se em $25 \%$ dos catadores com idades entre 16 e 20 anos, $34 \%$ entre 21 e 40 anos, $36 \%$ entre 41 e 60 anos e $5 \%$ com mais de 60 anos. 


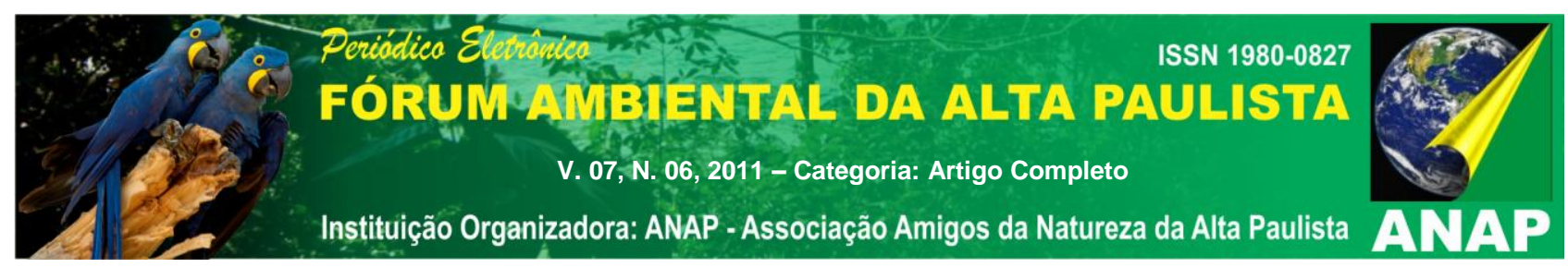

Muitos catadores afirmaram que já trabalharam como porteiros, mecânicos, pedreiros, e foram para o lixão já que esta foi a única alternativa que tiveram, após o desemprego, para obterem renda e suprir suas necessidades básicas e de seus familiares. No lixão, 20\% conseguiam auferir até 1 salário mínimo (SM) por mês, $33 \%$ até 2 SM, 33\% até 3 SM e 14\% afirmaram que obtinham renda superior a 3 SM. Em muitos casos, essa renda tratava-se da totalidade da renda familiar (geralmente com famílias formadas por 4 ou mais pessoas).

Além dos riscos de saúde envolvidos na atividade e ausência de amparo nas leis trabalhistas, a pesquisa evidenciou que esses catadores têm dificuldade de obtenção de crédito no comércio, pelo preconceito em relação ao trabalho na catação diretamente nas ruas ou lixão. Esta precária condição de trabalho dificulta a reinserção dos catadores no mercado, sobretudo para as mulheres-catadoras que buscam trabalhar como empregadas domésticas em residências particulares, sendo constantemente recusadas, pois ainda há um preconceito social que confunde o(a) catador(a) diretamente com o lixo. Faz-se necessário, portanto, ampliar a visibilidade desses catadores(as) para que sejam cada vez mais reconhecidos e valorizados como trabalhadores e agentes ambientais.

Como a maioria possui baixa escolaridade (ensino fundamental incompleto), é difícil sua inserção no mercado de trabalho em melhores condições, especialmente com carteira assinada (para muitos um grande sonho). Nesse sentido, os parceiros, junto com os cooperados da COOPERLIX, tentam evidenciar aos catadores que sua organização em cooperativa é uma alternativa importante, pois terão seu próprio negócio e poderão crescer e consolidar sua própria "empresa", terem melhores condições de trabalho e renda e abrirem novas oportunidades para outros catadores.

No aterro sanitário será proibida a entrada de catadores, o que obriga o poder público e a sociedade a buscarem alternativas para os atuais catadores, a fim de se evitar o agravamento de sua situação sócio-econômica e combater a forma injusta e subumana como estão inseridos (ou excluídos) na sociedade. 


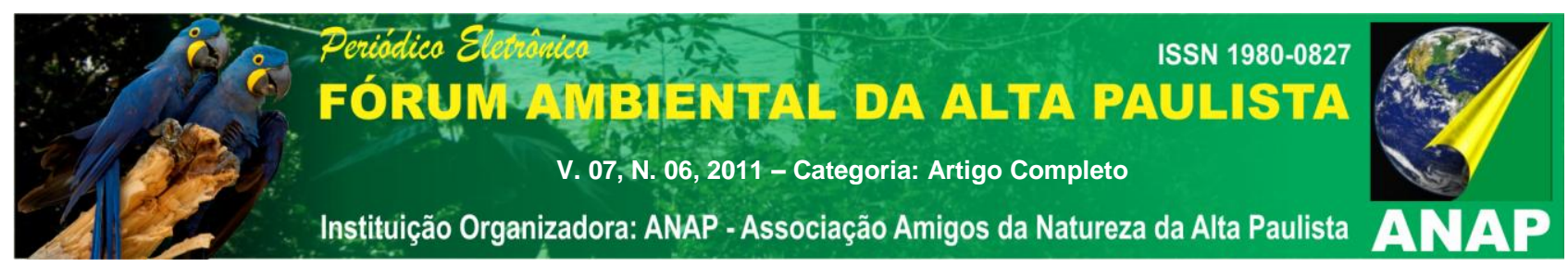

Essa situação, contudo, já está em vigência, tendo em vista que, recentemente, esses catadores foram proibidos de adentrarem ao lixão (atendendo-se às exigências dos órgãos ambientais e do trabalho) e foram cadastrados pela Prefeitura para receberem apoio mensal, durante 6 meses, e participarem de cursos de capacitação, visando sua reinserção no mercado de trabalho. Entre as alternativas de trabalho foram abertas vagas na COOPERLIX, as quais, contudo, são ainda insuficientes para atender a esta demanda. Faz-se necessário, portanto, ampliar e melhorar a coleta seletiva para que novas vagas se abertas, sem comprometer a atual renda dos cooperados.

É preciso considerar, ainda, que além dos catadores que trabalham no lixão, nas ruas de Presidente Prudente há carrinheiros, que são os catadores de materiais recicláveis que realizam esta atividade puxando carrinho próprio ou de terceiros - neste caso pagam uma taxa pelo aluguel do carrinho. O foco principal dos carrinheiros foi, durante muito tempo, os resíduos sólidos gerados no centro da cidade pelo comércio e serviços em geral, principalmente lojas e bancos locais onde se gera uma quantidade grande de resíduos de papelão, papel e plásticos.

Nos levantamentos anteriores realizados no âmbito do projeto de políticas públicas, foram entrevistados e cadastrados 54 carrinheiros, dos quais 45 são homens e 9 mulheres. A faixa etária vai de 16 a 76 anos, sendo a maioria com idade superior aos 46 anos, com 34 carrinheiros. Em relação ao estado civil, 35\% são solteiros, $28 \%$ casados, $19 \%$ divorciados e $18 \%$ em outras situações. A maioria dos carrinheiros é oriunda de Presidente Prudente e região ou de outras cidades do estado de São Paulo. Apenas 19 são de outros estados brasileiros, constituindo migrantes que passaram por várias cidades em busca de trabalho e renda, alguns tendo trabalhado em outros lixões municipais. Dentre as exprofissões já exercidas pelos carrinheiros estão: pedreiro, mecânico, auxiliar de serviços gerais, porteiro, faxineira, cozinheira. Há casos de donas de casa que passaram a catar resíduos recicláveis nas ruas em razão do desemprego do 


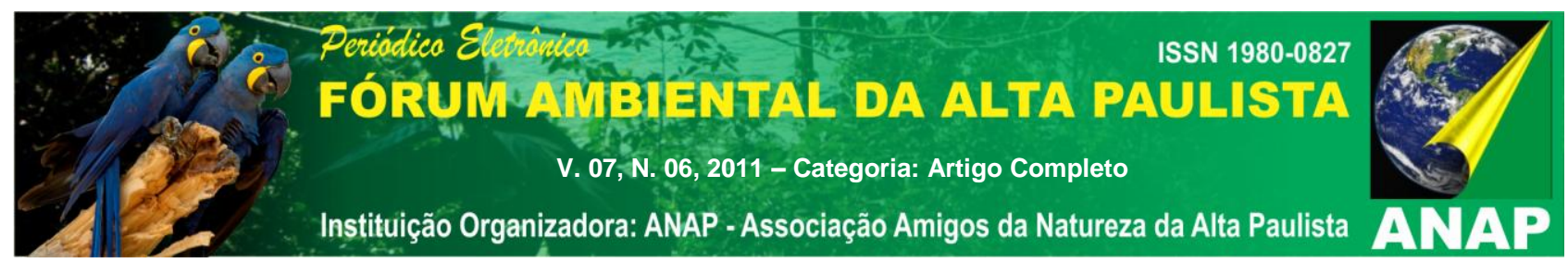

marido ou de seu baixo salário, e também alguns aposentados que não conseguem sobreviver com o valor da aposentadoria. Essas atividades exercidas são estreitamente vinculadas à sua formação escolar, sendo que a maioria possui apenas o ensino fundamental incompleto. Na atividade atual, 86\% dos carrinheiros afirmam que conseguem renda entre 1 a 3 SM, predominando a renda entre até 2 SM.

Com a proibição de entrada dos catadores no lixão, o número de carrinheiros aumentou nas ruas da cidade, notadamente nos bairros periféricos, gerando uma disputa por material reciclável e reutilizável. Há registro de casos de carrinheiros, ex-catadores, coletando em setores onde já está implantada a coleta seletiva realizada pela COOPERLIX. Evidencia-se, novamente, a necessidade de ampliar oportunidades de trabalho para que esses trabalhadores possam sair das ruas e trabalharem em condições adequadas e dignas.

Sobre a possibilidade de organização dos trabalhadores catadores, pode-se verificar nas entrevistas realizadas com os catadores que trabalhavam no lixão que mais da metade dos entrevistados demonstrou interesse em trabalhar na COOPERLIX ou em outra cooperativa. Da mesma forma, quando indagados sobre seu interesse em trabalhar na forma de cooperativa, 70\% dos carrinheiros entrevistados se manifestou favoravelmente, pois vêem nesse modo uma melhora substancial no reconhecimento do seu trabalho e também na valorização do material coletado.

O argumento mais utilizado pelos catadores para trabalharem em cooperativa foi o de que saindo do lixão suas condições de trabalho e de vida iriam melhorar significativamente, ainda que possam ter diminuído a renda pessoal. Este constitui outro desafio para a gestão, uma vez que há relatos de cooperados e catadores de que sua renda é maior quando trabalham individualmente. Para muitos, entretanto, especialmente mulheres e idosos, a renda aumenta quando estão organizados em cooperativa, tendo em vista que a 


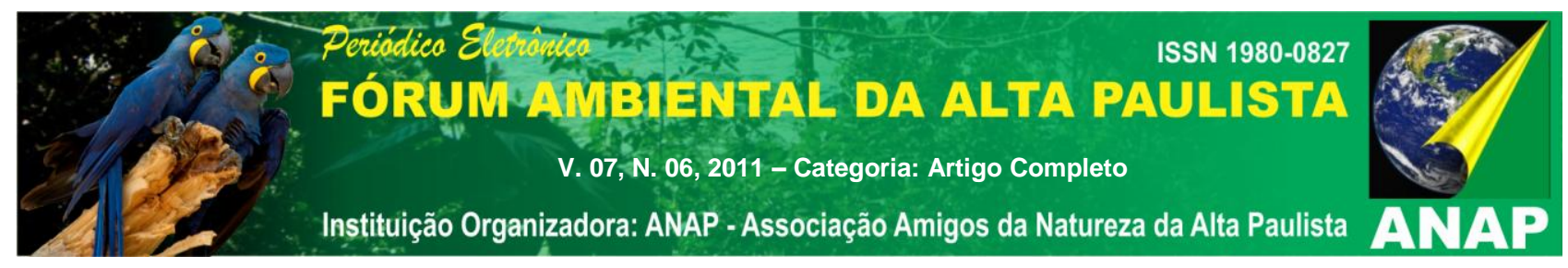

competição pelos resíduos não é mais necessária entre eles e há uma divisão de trabalho segundo suas potencialidades.

Considerando a grave situação dos trabalhadores no lixão e na perspectiva de contribuir para resolver esse problema, em 2001, começou a ser realizado o projeto de políticas públicas, cujos objetivos, ações e resultados foram anteriormente apresentados, destacando a formação de parcerias e a constituição da COOPERLIX, como alternativa para resolver a precária situação de trabalho dos catadores, a qual tem propiciado melhores condições de trabalho e dignidade a esses trabalhadores.

\section{COOPERLIX: CARACTERÍSTICAS, POTENCIALIDADES NA EDUCAÇÃo AMBIENTAL E DESAFIOS PARA SUA SUSTENTABILIDADE.}

A COOPERLIX tem sua sede na rua Mariano Arenales Benito, s/n, Distrito Industrial I. Atualmente, a COOPERLIX reúne 56 cooperados que são responsáveis pela realização da coleta seletiva em dezenas de bairros.

Por meio de doações e de projetos aprovados junto à agências de fomento à pesquisa, instituições financeiras, clubes de serviço e comunidades religiosas, entre outras, a cooperativa conta com: 3 caminhões para coleta seletiva, 2 esteiras para triagem, 2 prensas e várias baias para armazenamento dos resíduos, carrinhos para transporte de carga e elevador de carga - com previsão de implantação de máquina para processar plástico até início de 2011. Em prédio contíguo, ficam: escritório (com computadores, acesso à internet, impressora e telefone), vestiários, dispensa, cozinha e refeitório (utilizado também como sala de reuniões).

A coleta seletiva propicia um grande conjunto de benefícios à população de Presidente Prudente e ao meio ambiente, dentre os quais se destacam:

a) a melhoria das condições de trabalho, renda e vida dos catadores cooperados e seus familiares; 


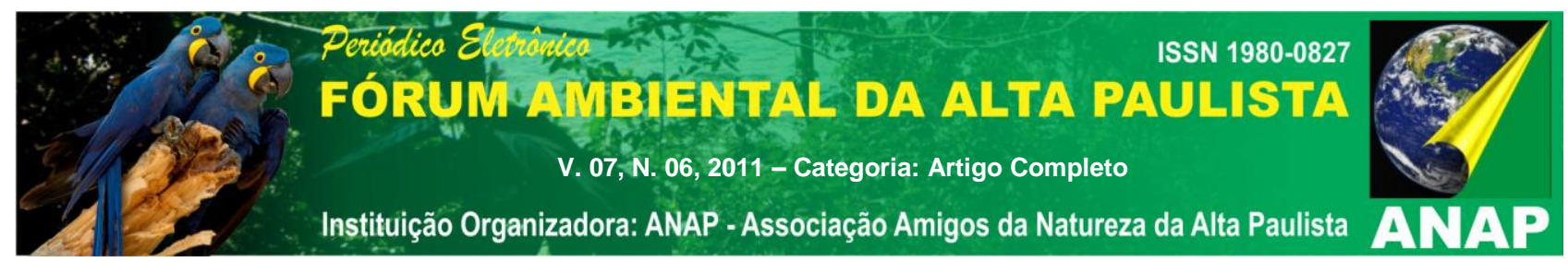

b) a diminuição da quantidade de resíduos sólidos a serem aterrados, pois a COOPERLIX coleta em média 80 toneladas por mês de materiais recicláveis e reutilizáveis.

Quando for implantado o aterro sanitário, sua vida útil será ampliada com a coleta seletiva, tendo em vista que os materiais recicláveis e reutilizáveis coletados pela COOPERLIX têm muito volume (especialmente plásticos e vidros) e, conseqüentemente, ocupariam grandes áreas no aterro. Tais aspectos justificam os esforços no sentido da ampliação da coleta seletiva para toda a área urbana do município.

A COOPERLIX está mostrando seu importante papel para a aproximação de seus integrantes, possibilitando a reconstrução de laços sociais e de ajuda mútua, além de colaborar com o destino apropriado dos resíduos sólidos produzidos pela população da cidade. Assim, firma-se na sociedade, oferecendo serviço essencial para um destino mais adequado aos resíduos gerados. Todavia, ainda há grandes desafios a serem enfrentados: a inclusão dos catadores que trabalhavam no lixão da cidade e dos carrinheiros das ruas; a melhoria do descarte seletivo nas residências; e a maior popularização da COOPERLIX, tornando-a mais conhecida da população. Para enfrentar esses desafios, além do questionário e cadastro dos catadores do lixão, foi realizada pesquisa sobre o impacto da coleta seletiva nos bairros, por meio da aplicação de aproximadamente 1.100 questionários com moradores, visando identificar seu conhecimento, práticas e adesão à proposta, relacionando-os com o nível de escolaridade do entrevistado.

Do total de entrevistados, $4 \%$ são analfabetos, $44 \%$ declararam ter o ensino fundamental, $44 \%$ o ensino médio e $8 \%$ tem nível superior (graduação). Na faixa etária de 9 a 19 temos $12,4 \%$ das pessoas entrevistadas e 13,4 entre 20 e 29 anos. A maioria dos entrevistados está na faixa de idade entre 30 a 39 anos, com $26,5 \%$, e de 40 a 49 anos, com $20 \%$. Uma pequena freqüência das pessoas está na faixa de 70 e 79 anos, com 3,2\%, 80 e 89 anos, com 0,4\%. (LEAL, 2003) 


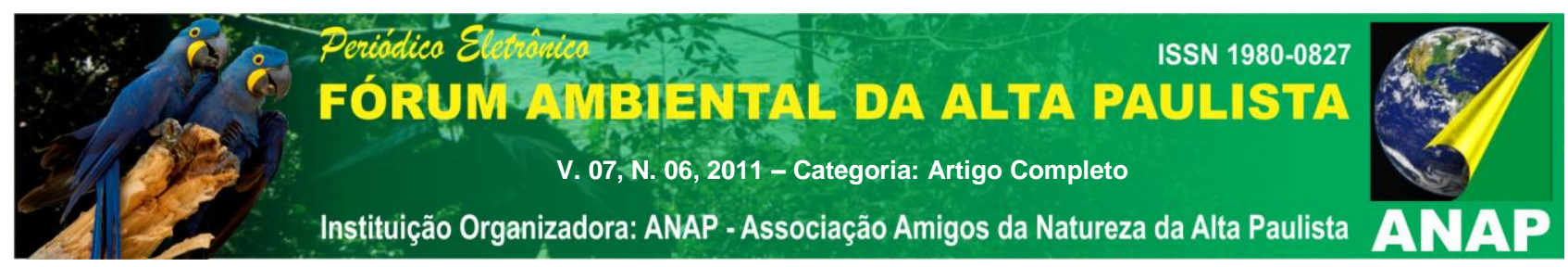

Em relação às definições de coleta seletiva expressos pelos entrevistados, $29 \%$ a definiu como separação dos resíduos, 10\% como reaproveitamento de material e 13\%, como materiais que podem ser recicláveis; $16 \%$ dos entrevistados não sabiam e os demais apresentaram respostas diversas. Fica evidente que a população compreende, inadequadamente, todo o processo de separação, descarte seletivo, coleta seletiva, triagem, comercialização e reutilização e/ou reciclagem como sendo "coleta seletiva". Portanto, a divulgação e apreensão do conhecimento e dos conceitos envolvidos no processo é fundamental para qualificar e ampliar a adesão dos moradores no descarte seletivo com qualidade.

Quanto à forma como as pessoas tomaram conhecimento da coleta seletiva na cidade, os dados mostram que $24,4 \%$ pessoas informaram que grande parte da divulgação da coleta seletiva é realizada por meio dos cooperados da COOPERLIX; $18,4 \%$ responderam que tomaram conhecimento por meio da televisão; 9,6\% por jornais; 8,5\% por panfletos; 5,7\% através da escola, 2,9\% por meio da igreja, 1,8 \% pelos vários meios anteriores e 3,6\% das pessoas respondeu que não sabia. Pode-se compreender que as campanhas e ações educativas conseguiram sensibilizar e mobilizar a comunidade local para 0 descarte seletivo dos resíduos.

Entretanto, a maioria dos entrevistados realiza o descarte seletivo dos resíduos gerados, mas não tem clareza quanto aos processos produtivos pré e pós-consumo, rotas dos resíduos e do lixo, estrutura e funcionamento da COOPERLIX e os benefícios ambientais decorrentes dessas ações. A ação de descarte seletivo está fundamentalmente embasada em sentimento de solidariedade com os cooperados (ajudar ao próximo) e, em segundo plano, mas não menos importante, com a preocupação em reduzir a degradação ambiental.

Neste contexto, para consolidar a COOPERLIX e criar alternativas para os catadores fica evidente a real necessidade de construção e socialização de conhecimentos sobre a COOPERLIX e todo o processo de reciclagem dos resíduos sólidos em Presidente Prudente. Esse processo deve ser articulado a 


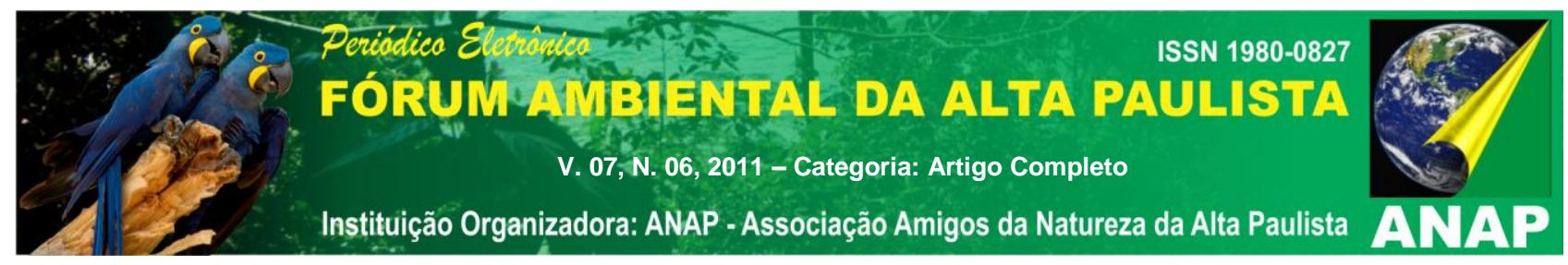

uma educação ambiental contínua, que estimule a consciência e participação dos cidadãos, haja vista que se estiverem devidamente educados poderão assumir a responsabilidade para conservar e preservar os recursos naturais, através de ações como o descarte seletivo de resíduos sólidos.

Acredita-se que o trabalho cooperativo realizado pelos integrantes da COOPERLIX possa trazer forças para competir com igualdade no mercado, procurando, com a união, aumentar a oferta de materiais recicláveis e conseguir um volume maior, suficiente para negociar os preços e as condições com as industrias deste segmento dando oportunidade de resgate da dignidade humana do catador e desenvolvimento da auto-ajuda e ajuda mútua.

Em relação à forma de organização e gestão, pretende-se que a COOPERLIX seja auto-sustentável e que os parceiros sejam apoiadores em sua gestão interna, mas mantendo-se o poder de decisão com os cooperados. A autogestão vem sendo construída no curso de sua trajetória, a fim de responder às expectativas do grupo e aos objetivos de uma gestão coletiva, autônoma (embora assistida), democrática e sustentável.

\section{REFERENCIAS BIBLIOGRÁFICAS}

DIAS, G. F. Educação Ambiental : Princípios e Práticas. 4.ed., São Paulo: GAIA, 1994.

LEAL, A.C. et al. Resíduos sólidos no Pontal do Paranapanema. Presidente Prudente - SP:Editora Viena, 2004.

LEAL, A.C. Educação ambiental e o gerenciamento integrado dos resíduos sólidos em Presidente Prudente-SP: Desenvolvimento de metodologias para coleta seletiva, beneficiamento do lixo e organização do trabalho. Presidente Prudente:UNESP/FAPESP, 2003. 